\title{
A multivariate multilevel analysis of the risk factors associated with anthropometric indices in Iranian mid-adolescents
}

\author{
Marzieh Alamolhoda', Seyyed Taghi Heydari ${ }^{1 *}$ (D), Seyyed Mohammad Taghi Ayatollahi², Reza Tabrizi',
} Maryam Akbari ${ }^{1}$ and Arash Ardalan ${ }^{3}$

\begin{abstract}
Background: The present study was conducted to jointly assess some specific factors related to body fat measures using a multivariate multilevel analysis in a representative sample of Iranian mid-adolescents.

Methods: This study was conducted among 2538 students (1286 boys) aged 14-20 years old, who were randomly selected among 16 public high schools by multi-stage random sampling procedure from all education districts of Shiraz, Iran. Data on demographic characteristics, family history of obesity, physical activity, socio-economic (SES) variables and screen time were collected. Height, weight, triceps (TST), abdominal (AST), and subscapular (SST) skinfold thickness were measured and their body mass index (BMI) was calculated. A multivariate multilevel approach was used to analyze the factors associated with obesity measures of the TST, AST, SST at the child and district levels.

Results: In this study, the prevalence of overweight and obesity was estimated to be 10.2 and $5.1 \%$, respectively. Overall, the major portion of the total variance in TST (97.1\%), AST (97.7\%), and SST (97.5\%) was found at the child level. The results of multivariate multilevel method revealed that being girls, having a family history of obesity, and SES were significantly associated with increasing of three body fat measures (all the $p$-values were less than 0.05). There were significant positive associations between moderate to vigorous physical activities with AST and SST (for AST: $\beta=2.54, \mathrm{SE}=1.40, p=0.05$; for SST: $\beta=2.24, \mathrm{SE}=1.20, p=0.05$ ). Compared to children in 14-16 age group, children in age group 16-18 years had less TST $(\beta=-0.67, \mathrm{SE}=0.34, p=0.04)$. Furthermore, other age groups and screen time did not play an important role in three outcome variables.

Conclusions: The results showed some factors that contribute to three body fat measures. Therefore, it is necessary to develop effective interventions to prevent the effects of individual and environmental undesirable factors on childhood obesity in both family and community levels.
\end{abstract}

Keywords: Childhood obesity, Skinfold thickness, Socio-economic status, Physical activity, Family history of obesity, Multivariate multilevel analysis

\footnotetext{
* Correspondence: heydari.st@gmail.com

${ }^{1}$ Health Policy Research Center, Institute of Health, Shiraz University of Medical Sciences, Shiraz, Iran

Full list of author information is available at the end of the article
}

(c) The Author(s). 2020 Open Access This article is licensed under a Creative Commons Attribution 4.0 International License, which permits use, sharing, adaptation, distribution and reproduction in any medium or format, as long as you give appropriate credit to the original author(s) and the source, provide a link to the Creative Commons licence, and indicate if changes were made. The images or other third party material in this article are included in the article's Creative Commons licence, unless indicated otherwise in a credit line to the material. If material is not included in the article's Creative Commons licence and your intended use is not permitted by statutory regulation or exceeds the permitted use, you will need to obtain permission directly from the copyright holder. To view a copy of this licence, visit http://creativecommons.org/licenses/by/4.0/. The Creative Commons Public Domain Dedication waiver (http://creativecommons.org/publicdomain/zero/1.0/) applies to the data made available in this article, unless otherwise stated in a credit line to the data. 


\section{Background}

In recent years, the rapid growth of obesity among children and adolescents has become a serious public health challenge in both developing and developed countries [1-3]. The prevalence of childhood obesity has an arising trend in Iran, like other developing countries $[4,5]$. Obesity in early life, as an important metabolic problem leads to major health disorders such as hypertension [4], non-alcoholic fatty liver disease [6], obesity in the adulthood and more other nutrition -related chronic diseases such as type 1 diabetes, cardiovascular disease [7], some types of cancer [8] as well as a decrease in the life expectancy [9].

Among several approaches used to measure the obesity, Body Mass Index (BMI), Skinfold Thickness (ST) and waist circumference (WC) have been more frequently used in clinical setting [8]. Although, BMI, as a simple and inexpensive parameter is used more than other approaches for measuring the obesity, it has several drawbacks as mentioned in the literature [10]. ST is an easily obtained adiposity index, which is commonly used, and is an accurate estimate for measuring the subcutaneous body fat among children and adolescents [7, 11-13]. It also can be easily applied in clinics, laboratories and schools because of its portable, low cost and non-invasive nature [14]. Further, the use of ST as an epidemiological screening tool for cardio metabolic risk factors, a better predictor of high body fatness during adulthood than BMI and a reliable tool in assessing the effect of lifestyle factors in children and adolescent has been reported in earlier reports [15-17].

The mechanism of obesity development has remained unidentified, and the researchers characterize the obesity as a health disorder with multiple causes [18]. Certainly, a lot of influential factors have been reported to be effective on childhood obesity. Individual factors such as physical and social functioning as well as environmental factors, lifestyle preferences, and cultural environment play an important role in increasing or decreasing the prevalence of childhood obesity [19, 20]. A systematic review of the published studies in South Asian countries revealed that the lack of proper physical activities, prolonged TV watching or using different electronic media, unhealthy dietary patterns, family history of obesity, and the family socio-economic status are among the main individual factors found to be significantly associated with the obesity in children and adolescents [21]. Moreover, previous studies showed that behavioral and environmental factors were significantly associated with increasing childhood obesity [22, 23]. In fact, factors related to childhood obesity are a subset of multi-factorial etiology in three levels: family, school, and community. Therefore, the coverage of the risk factors contributing to childhood obesity needs to consider muti-sectoral approaches. However, many studies have examined simple relationships between predictor variables with adiposity indices and there are limited studies that have considered hierarchical structure in these models [19, $20,24,25]$. It is necessary to consider effective strategies in order to prevent and control childhood obesity in different aspects.

Since anthropometric measures seemingly share common biological and environmental relationships, simultaneous evaluation of multiple outcomes and the influential covariates using multivariate multilevel approaches will lead to more accurate results than univariate approaches. Furthermore, when the data have a hierarchical structure, predictor variables in ordinary multivariate regression models with single level do not provide correct inferences for outcome variables, due to the dependency existing between the observations. Therefore, it is necessary to fit a model that can accurately estimate the parameters. The present study aimed to simultaneously investigate the relationship between the influential covariates and three anthropometric measures including triceps (TST), abdominal (AST), and sub-scapular (SST) skinfold thickness using multivariate multilevel analysis.

\section{Methods}

\section{Subjects, study design, and sampling procedure}

The sample of the current study was collected from high school students in Shiraz during September to December 2014. Administratively, Shiraz, the capital of Fars Province in southern Iran, is divided into 4 educational districts. Each district has distinct social, cultural, economic and health characteristics. In this cross-sectional study, 2538 healthy subjects (1286 boys and 1252 girls) aged 14-20 years old were selected among 16 public high schools by multi-stage random sampling procedure from 4 education districts of Shiraz. In the first step, 4 schools were chosen from each district (two from boy's schools and two from girl's schools) using simple random sampling. In the next step, based on the school sample size, 2 or 3 classrooms were randomly selected from each school, and all the students in the classroom were studied.

Children gave oral assent before participating in the study and written informed consent was obtained from their parents. The study protocol was approved by the Ethics Committee of Shiraz University of Medical Sciences. Moreover, the permission was obtained from schools principal for collecting the data from the selected classrooms.

\section{Measurements}

The collected data were classified into two groups: demographic characteristics and anthropometric measurements; the former describing sex, age, screen time, family history of obesity, Physical Activities (PA), and Socio-Economic Status (SES) variables. These data were 
collected through a questionnaire. Content validity of the questionnaire was confirmed by three specialists in epidemiology, biostatistics and endocrinology.

Screen time was defined as the times spent on watching TV, using computer, and playing video games by using a question: "How long do you spend your time on watching TV, using computer, and playing video game per day?". Family history of obesity was assessed using a question, "Is there a history of obesity in your family?". PA was assessed using two questions: during the past week, "What kind of physical activity do you do? " and "How many days do you have physical activity for more than $30 \mathrm{min?"}$. PA was classified into three levels, namely mild, moderate, and vigorous activities. SES was calculated using principal component analysis by available variables used for SES measurement $[19,26]$. Variables such as parents' education level, parents' occupation, as well as choice of car type and homeownership (Ownership or Rent) were included in the analysis to make one main component. The SES score calculated using the weighted averages of the variables was categorized into three levels (low, middle, and high) to define the SES.

The second data related to anthropometric measurements included body weight and height, BMI, TST, AST and SST. Height and weight were measured in all students, while wearing light clothing and no shoes, with 0.1 $\mathrm{cm}$ and $0.1 \mathrm{~kg}$ accuracy, respectively using tape measure and a SECA digital scale (Germany). BMI was calculated by dividing weight $(\mathrm{kg})$ by height squared $\left(\mathrm{m}^{2}\right)$ and was classified based on the WHOs growth charts [27]. The subjects of the same sex and age with BMI less than 85th percentile, between 85th and 95th percentile and above 95th percentile were classified into three groups: normal, overweight and obese, respectively [28]. A graded caliper was used to measure the ST in three sites of the body (triceps, abdominal, and subscapular). To measure the triceps, the technician bent the elbow to 90 degrees and marked the point midway between the top of the shoulder and elbow, and then measured a vertical fold by the caliper at a 90-degree angle on that midway point with the arm hanging naturally at the subject's side. For AST measurements, vertical folds were measured at $2 \mathrm{~cm}$ to the right and left of the navel. Finally, a diagonal fold (calipers held at a 45-degree angle) was taken across the back, just below the shoulder blade to measure the SST. ST was measured on both right and left sides of the body separately, and the average of two measurements was recorded to the nearest $0.5 \mathrm{~mm}$ [29]. All anthropometric measurements of the students were done by two trained technicians. Measurement was repeated by another technician if there was a great difference in the right and left sides.

\section{Statistical analysis}

Mean and standard deviation were calculated for quantitative data, and frequency and percentage were reported for qualitative variables. Pearson Chi-Square, and OneWay ANOVA tests were used to investigate the association between the variables at the child level. A $P$-value of less than 0.05 was considered as statistically significant. Since, in this study, the data had a hierarchical structure with multiple outcomes, multivariate multilevel analysis was used to depict the hierarchical structure of the data [30]. The ability to model the correlation between response variables (in our case, at individual and district levels), increasing the power, performing a single test to avoid the risk of chance capitalization, which is inherent to carrying out a separate test for each dependent variable, and measuring the effect of any exploratory variable separately across multiple outcome variables are main advantages using multivariate hierarchical analysis [31]. In this study, TST, AST, and SST as three multiple outcome variables were at the first level in the hierarchy. Therefore, for each subject, three quantitative measures were recorded simultaneously as units in level 1. The subjects included as units in the second level, and districts were considered at the third level in the hierarchy. These levels are shown in Fig. 1. The multilevel structure makes it possible to evaluate whether the districts made a difference to individual anthropometric measures. Three outcome variables were regressed on a set of explanatory variables in the random intercept model, which were in levels 2 and 3. Primary analysis of the data was carried out using SPSS software (Ver. 18.0). The MLwiN software version 2.00 was used to analyze the hierarchical model.

\section{Results}

Table 1 shows the results of descriptive statistics (percentage) for the children in 4 districts. A total of 1286 (50.7\%) subjects were boys and were roughly distributed equally in 4 districts. Mean age (SD) of the participants was equal to 15.99 (0.94) years old, which was not distributed equally in the districts $(P$-value $<0.05)$. The distribution of screen time was somewhat different between 4 districts $(p=$ 0.05). On average, more times on watching TV or using computer were recorded for students living in districts 4 and 1 (Means (SD) in 4 districts were 4.47 (2.29), 4.39 (2.12), 4.36 (2.52) and $4.72(2.52) \mathrm{h} /$ day, respectively). About $44 \%$ of the participants were categorized into family history of obesity group. Having mild physical activities was reported by $76.6 \%$ of the students and only $3.1 \%$ of them had vigorous physical activities. Compared to other districts, more children from district 3 lived in a family with low SES. The results of Chi-Square test revealed that, the subjects were distributed differently with regard to physical activities, SES and prevalence of overweight and obesity in four districts. However, there was not a statistically significant difference between the four groups with respect to gender and family history of obesity. 


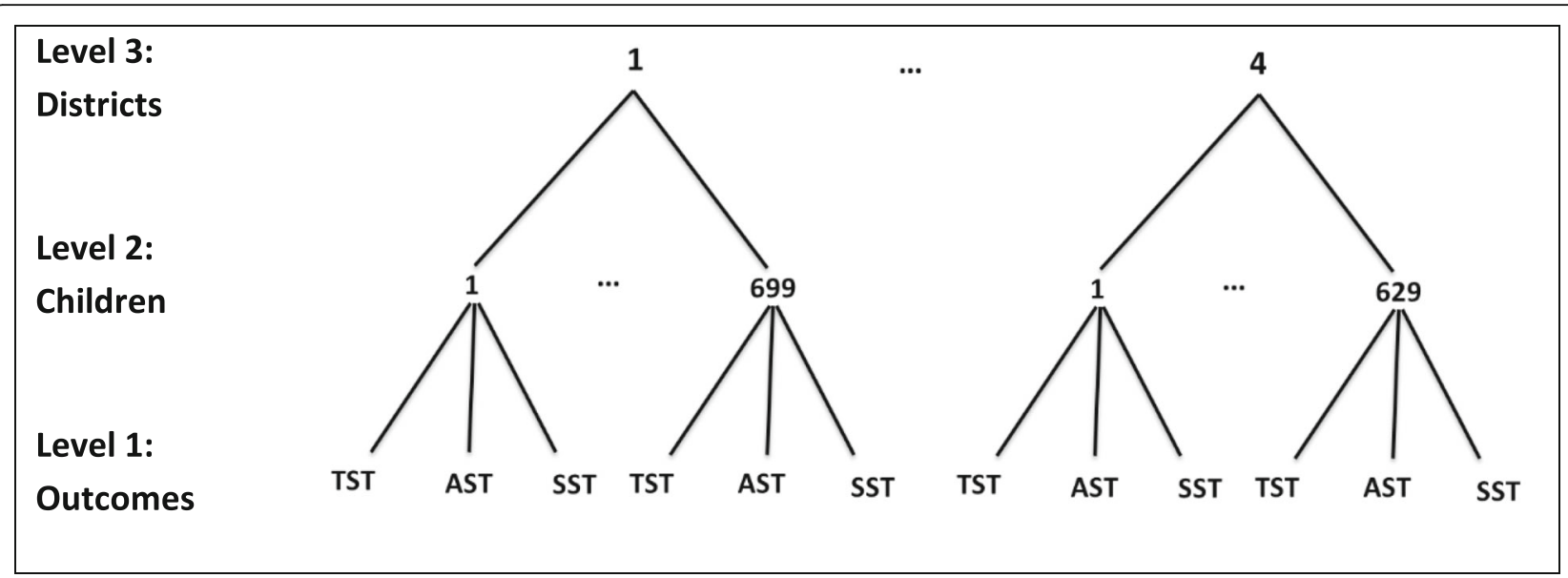

TST triceps skinfold thickness; AST abdominal skinfold thickness; SST subscapular skinfold thickness

Fig. 1 Multivariate multilevel structures of anthropometric measures (TST, AST and SST) at level one nested within children at level 2, nested within districts at level 3

Table 1 Descriptive statistics among individuals by districts

\begin{tabular}{|c|c|c|c|c|c|c|c|}
\hline Variables & Descriptor & $\begin{array}{l}\text { District } 1 \\
(n=699)\end{array}$ & $\begin{array}{l}\text { District } 2 \\
(n=601)\end{array}$ & $\begin{array}{l}\text { District } 3 \\
(n=609)\end{array}$ & $\begin{array}{l}\text { District } 4 \\
(n=629)\end{array}$ & $\begin{array}{l}\text { Total } \\
(n=2538)\end{array}$ & $P$-value ${ }^{a}$ \\
\hline \multicolumn{8}{|l|}{ Screen time } \\
\hline$<2$ h/day & N (\%) & $51(9.5)$ & $43(8.5)$ & $48(13.7)$ & $43(8.7)$ & $185(9.8)$ & \multirow[t]{2}{*}{0.05} \\
\hline$\geq 2$ h/day & N (\%) & $486(90.5)$ & $463(91.5)$ & $302(86.3)$ & $452(91.3)$ & $1703(90.2)$ & \\
\hline \multicolumn{8}{|l|}{ Sex } \\
\hline Boy & N (\%) & $359(51.4)$ & $309(51.4)$ & $295(48.4)$ & $323(51.4)$ & $1286(50.7)$ & \multirow[t]{2}{*}{0.66} \\
\hline Girl & N (\%) & $340(48.6)$ & $292(48.6)$ & $314(51.6)$ & $306(48.6)$ & $1252(49.3)$ & \\
\hline \multicolumn{8}{|c|}{ Age groups (year) } \\
\hline$[14-16)$ & N (\%) & $362(51.9)$ & $347(57.8)$ & $320(52.6)$ & $347(55.2)$ & $1376(54.3)$ & \multirow[t]{3}{*}{0.00} \\
\hline$[16-18)$ & N (\%) & $328(47.0)$ & $252(42.0)$ & $254(41.8)$ & $260(41.3)$ & $1094(43.2)$ & \\
\hline [18-20] & N (\%) & $8(1.1)$ & $1(0.2)$ & $34(5.6)$ & $22(3.5)$ & $65(2.6)$ & \\
\hline \multicolumn{8}{|c|}{ Family history of obesity } \\
\hline Yes & N (\%) & $296(42.6)$ & $261(43.8)$ & $270(44.6)$ & $286(45.9)$ & $1113(44.2)$ & \multirow[t]{2}{*}{0.67} \\
\hline No & N (\%) & $399(57.4)$ & $335(56.2)$ & $336(55.4)$ & $337(54.1)$ & $1407(55.8)$ & \\
\hline \multicolumn{8}{|c|}{ Physical activity } \\
\hline Mild & N (\%) & $431(75.0)$ & $315(72.9)$ & $355(82.2)$ & $379(76.7)$ & 1480 (76.6) & \multirow[t]{3}{*}{0.02} \\
\hline Moderate & N (\%) & $124(21.6)$ & 99 (22.9) & $65(15.0)$ & $105(21.3)$ & $393(20.3)$ & \\
\hline Vigorous & N (\%) & $20(3.5)$ & $18(4.2)$ & $12(2.8)$ & $10(2.0)$ & $60(3.1)$ & \\
\hline \multicolumn{8}{|l|}{ SES status } \\
\hline Low & N (\%) & $124(26.1)$ & $48(11.3)$ & $349(76.9)$ & $191(44.3)$ & $712(39.9)$ & \multirow[t]{3}{*}{0.00} \\
\hline Med & N (\%) & $303(63.8)$ & $307(72.1)$ & 98 (21.6) & $227(52.7)$ & 935 (52.4) & \\
\hline High & N (\%) & $48(10.1)$ & $71(16.7)$ & $7(1.5)$ & $13(3.0)$ & $139(7.8)$ & \\
\hline \multicolumn{8}{|l|}{ Obesity Status } \\
\hline Normal & N (\%) & $568(82.2)$ & $501(83.5)$ & 535 (88.6) & $532(84.7)$ & $2136(84.7)$ & \multirow[t]{3}{*}{0.02} \\
\hline Overweight & N (\%) & $74(10.7)$ & $70(11.7)$ & $47(7.8)$ & $67(10.7)$ & $258(10.2)$ & \\
\hline Obese & N (\%) & $49(7.1)$ & $29(4.8)$ & $22(3.6)$ & $29(4.6)$ & $129(5.1)$ & \\
\hline
\end{tabular}


Overall, in this study, the prevalence of overweight and obesity was equal to 10.2 and $5.1 \%$, respectively, and there was no significant association in the gender groups (prevalence of overweight and obesity was equal to 10.0 and $5.2 \%$ for boys and 10.3 and $5.0 \%$ for girls, respectively, with $P$-value $>0.05)$. The results of anthropometric measures in 4 districts are presented in Table 2. Generally, there were statistically significant differences in all anthropometric variables between four groups $(P$-values $<0.01)$. The results of ANOVA tests revealed that, district 4 and 1 had the highest values of TST, AST, and SST. Means in all anthropometric measures were significantly lower in the third district than those of other districts. Furthermore, prevalence of overweight and obesity in the third district was lower than other regions.

Table 3 illustrates the effect of the covariates on three outcomes in a multivariate multilevel model. As shown in Table 3, being girl, having a family history of obesity, and SES were significantly associated with three anthropometric measures. Although boys had greater mean BMI than girls (mean (SD) of BMI was equal to 21.81 (4.51) for boys and 21.23 (3.49) for girls, respectively, with $P$-value $<0.001)$, the subcutaneous adipose tissue was thicker in girls than that of boys by over 3,2 and 2 $\mathrm{mm}$ in TST, SST and AST, respectively (for TST: $\beta=$ 3.02, $\mathrm{SE}=0.37, p<0.001$; for AST: $\beta=2.33, \mathrm{SE}=0.49$, $p<0.001$; for SST: $\beta=2.17, \mathrm{SE}=0.42, p<0.001)$. Furthermore, subjects who lived in a family with a history of obesity had more fat (for TST: $\beta=2.25, \mathrm{SE}=0.34, p<$ 0.001; for AST: $\beta=3.30, \mathrm{SE}=0.45, p<0.001$; for SST: $\beta$ $=3.49, \mathrm{SE}=0.39, p<0.001)$, than others did. Results of Table 3 also showed that, SES had a significant direct effect on all three anthropometric measures. It was found that, compared to children with low SES, children with high and moderate SES had more TST, AST and SST. The levels of physical activity had a positive relationship with individual outcomes, with significant associations between the moderate to vigorous physical activities. Children with moderate physical activity had higher AST and SST than those with vigorous physical activity by over $2,2 \mathrm{~mm}$ (for AST: $\beta=2.54, \mathrm{SE}=1.40, p=0.051$; for SST: $\beta=2.24, \mathrm{SE}=1.20, p=0.047)$. Compared to children in 14-16 age group, children in age group 1618 years had less TST $(\beta=-0.67, \mathrm{SE}=0.34, \mathrm{p}=0.04)$. Moreover, screen time did not play an important role in three outcome variables.

-2loglikelihood statistic with Iterative Generalized Least Squares (IGLS) as an estimation method was obtained as 26,653.0 with 42 estimated parameters in final model, so that compared to the null model (null model is a model having only intercepts with the -2loglikelihood of 47,697.8 with 15 estimated parameters), the deviance was statistically significant $(21,044.8$ with 27 degree of freedom and $P$-value $<0.001)$ and given the dramatic reduction in deviance, this model fits the data well.

Overall, the major portion of the total variation in TST (97.1\%), AST (97.7\%), and SST (97.5\%) was found at the child level. Further, at the child level (within-districts), high correlations were obtained between three outcomes (the within-district correlations were obtained as $0.68,0.72$, and 0.80 for the (TST, AST), (TST, SST), and (AST, SST), respectively). Although districts explain a relatively small amount of the total variation of TST (2.9\%), AST (2.3\%) and SST (2.5\%), relatively high correlations between the outcome variables indicated that the districts are properly positioned in the third level of the hierarchy. The results of the correlation between the outcomes showed that, the intra-district correlations were obtained as $0.49,0.21$, and 0.80 for the (TST, AST), (TST, SST), and (AST, SST), respectively.

\section{Discussion}

The present study was an attempt to jointly evaluate the relationships between three body fat measures with a set of covariates in Iranian mid-adolescents within different 4 districts, using a multivariate multilevel analysis. Given the multifactorial nature of childhood obesity which form a hierarchical structure, we analyzed the data through a multilevel model. One of the main finding of this study is the high positive correlations between TST, AST and SST at the child level, suggesting that children with higher TST tend to also have higher AST and SST after adjusting for a set of covariates at the child and

Table 2 Anthropometric measurement of individual at district level

\begin{tabular}{lllllll}
\hline & Descriptor & District 1 & District 2 & District 3 & District 4 & $P$-value \\
\hline TST $(\mathrm{mm})$ & Mean (SD) & $16.36(7.33)$ & $15.65(7.02)$ & $13.08(5.93)$ & $16.71(8.25)$ & 0.00 \\
AST $(\mathrm{mm})$ & Mean (SD) & $17.49(9.34)$ & $16.49(7.78)$ & $14.61(8.83)$ & $17.57(9.36)$ & 0.00 \\
SST $(\mathrm{mm})$ & Mean (SD) & $16.60(8.14)$ & $16.10(7.83)$ & $13.85(6.71)$ & $17.91(8.84)$ & 0.00 \\
Height $(\mathrm{cm})$ & Mean (SD) & $165.88(8.69)$ & $167.28(8.08)$ & $163.62(8.37)$ & $165.48(8.60)$ & 0.00 \\
Weight $(\mathrm{kg})$ & Mean (SD) & $60.50(13.99)$ & $60.79(13.43)$ & $56.47(12.12)$ & $59.32(13.97)$ & 0.00 \\
BMI $\left(\mathrm{kg} / \mathrm{m}^{2}\right)$ & Mean (SD) & $21.86(4.22)$ & $21.61(3.85)$ & $21.01(3.69)$ & $21.59(4.33)$ & 0.00 \\
\hline
\end{tabular}

$P$-values are derived from ANOVA tests ( $p$-value $<0.05$ was statistical significant), $S D$ standard deviation

Abbreviation: TST triceps skinfold thickness, AST abdominal skinfold thickness, SST subscapular skinfold thickness, BMI body mass index 
Table $\mathbf{3}$ associated factors with three anthropometric measures in hierarchical model

Fixed Effects

\begin{tabular}{|c|c|c|c|c|c|c|}
\hline & \multicolumn{2}{|l|}{ TST } & \multicolumn{2}{|l|}{ AST } & \multicolumn{2}{|l|}{ SST } \\
\hline & Estimate & SE & Estimate & SE & Estimate & SE \\
\hline Intercept & $10.49^{*}$ & 1.17 & $11.11^{*}$ & 1.55 & $10.60^{*}$ & 1.34 \\
\hline \multicolumn{7}{|l|}{ Sex } \\
\hline girls/boy & $3.02^{*}$ & 0.37 & $2.33^{*}$ & 0.49 & $2.17^{*}$ & 0.42 \\
\hline \multicolumn{7}{|c|}{ Family history of obesity } \\
\hline yes/no & $2.25^{*}$ & 0.34 & $3.30^{*}$ & 0.45 & $3.49^{*}$ & 0.39 \\
\hline \multicolumn{7}{|l|}{ Physical activity } \\
\hline mild /vigorous & 0.81 & 1.16 & 1.67 & 1.52 & 1.27 & 1.32 \\
\hline moderate/ vigorous & 1.51 & 1.04 & $2.54^{*}$ & 1.40 & $2.24^{*}$ & 1.20 \\
\hline \multicolumn{7}{|l|}{ SES } \\
\hline moderate/low & $0.81^{*}$ & 0.39 & $1.01^{*}$ & 0.52 & $0.80^{*}$ & 0.45 \\
\hline high/low & $1.70^{*}$ & 0.66 & $2.25^{*}$ & 0.90 & $2.48^{*}$ & 0.77 \\
\hline \multicolumn{7}{|l|}{ Age groups } \\
\hline group2/group1 & $-0.67^{*}$ & 0.34 & -0.09 & 0.46 & 0.54 & 0.39 \\
\hline group3/group1 & 0.30 & 1.30 & -1.09 & 1.76 & 1.75 & 1.51 \\
\hline \multicolumn{7}{|c|}{ Screen time (min per day) } \\
\hline $\begin{array}{l}\text { watching TV or } \\
\text { video games }\end{array}$ & 0.06 & 0.08 & 0.15 & 0.10 & 0.11 & 0.09 \\
\hline \multicolumn{7}{|l|}{ Random Effects } \\
\hline & TST & & AST & & SST & \\
\hline Variance & Estimate & SE & Estimate & SE & Estimate & SE \\
\hline Child-level & 38.85 & 1.46 & 70.82 & 2.66 & 52.32 & 1.97 \\
\hline \multirow[t]{2}{*}{ District-level } & 1.18 & 0.62 & 1.63 & 0.94 & 1.33 & 0.74 \\
\hline & TST, AST & SE & TST, SST & SE & AST, SST & \\
\hline
\end{tabular}

Covariance

\begin{tabular}{lllllll} 
Child-level & 35.85 & 1.69 & 32.41 & 1.47 & 48.71 & 2.07 \\
District-level & 0.68 & 0.62 & 0.27 & 0.51 & 1.18 & 0.76 \\
Correlation & & & & & & \\
Child-level & 0.68 & - & 0.72 & - & 0.80 & - \\
District-level & 0.49 & - & 0.21 & - & 0.80 & - \\
\hline
\end{tabular}

Abbreviation: TST triceps skinfold thickness, $\boldsymbol{A S T}$ abdominal skinfold thickness, SST subscapular skinfold thickness, SES socio-economic status

Age groups: group1 [14-16) years, group2 [16-18) years and group 3 [18-20] years

${ }^{*} p$-value $<0.05$

district levels. Moreover, positive correlations were also observed between three outcomes at district level. This finding implies that communities play an important role in promotion of adolescent's health. Therefore, health behaviors associated with childhood obesity are influenced by a combination of behavioral and environmental factors including community, school and family.

The prevalence of childhood obesity has sharply increased from 1990 to 2010 in low- and middle-income countries compared to the developed countries [32], which can have undesirable effects on physical, mental, and psychosocial health in adolescents [33-35]. Studies reported that, the prevalence of overweight and obesity in adolescents varies in different parts of Iran $[4,19,36]$. People, who were living in the same region with the same habits were similar in terms of growth, development, and body shape, which might be due to their lifestyle, dietary patterns, and socio-cultural factors $[19,20]$. The results of Table 2 revealed that, there were statistically significant differences between the anthropometric measures with respect to 4 districts. Therefore, the effect of individual level risk factors may vary according to the environment in which one lives.

To the best of our knowledge, limited studies have examined the association between individual factors and adiposity indices across children through multivariate multilevel analysis [20, 24]. Results of multivariate multilevel approach showed that, some risk factors associated with the obesity in adolescents were consistent with those reported in previous researches in Iran [19, 20, 37]. Results of multivariate multilevel analysis indicated a statistically significant association between the sex, family history of obesity, and SES with three anthropometric measures. Sex was positively and highly associated with three outcomes, proving that girls had higher TST, AST, and SST than the boys. However, boys had better growth in terms of height, weight and subsequently in BMI than the girls. These results were in line with the previous studies which reported that, the percentage of subcutaneous adipose tissue was higher in females bodies than that of males due to their sedentary lifestyle, less involvement in vigorous physical activities and less expenditure of energy [7, 16]. Although, an agreement has been proved between BMI and TST in some studies [29, 38], BMI may not be a useful parameter in measuring the subcutaneous body fat of children, because changing the body shape occurs in childhood. Furthermore, it fails to differentiate the fat from the muscle mass and may classify children with large muscle into obese children group [18]. Shriraam et al. explained that, BMI is a crude measure, which does not provide a precise assessment of body density [10].

A positive association was found between family history of obesity and anthropometric measures similar to other studies [20,39]. Khashayar et al. reported that, the odds of obesity in Iranian students with obese parents were about 2 times greater than the others [19]. Environmental factors such as family lifestyle, eating habits and also becoming obese due to the genetic factors are considered as the subset of family history of obesity, and are the most important reasons influencing the persistence of obesity in adulthood [4, 40, 41]. Therefore, modification of diet, having proper physical activities, and health care in the families could be an effective 
approach to decrease the risk of childhood and adulthood obesity.

In line with previous studies in Iran [19, 20], our findings showed positive relationships between SES with three outcome variables, especially at high levels, which revealed that higher risk of overweight/obesity is related to the social environment. Bahreynian et al. study reported that the prevalence of overweight was greater in areas with high SES, whereas underweight and short stature were more prevalent in areas with low SES [42]. In the current study, students with higher anthropometric measures were living in families with higher SES, as confirmed in some other studies conducted in Iran and some other countries, in which positive significant associations were found between SES and adiposity among children and adolescents in developing countries [20, 24, 43]. It is noteworthy that, the means of body fat, height, weight, and prevalence of overweight and obesity were lower in the students living in district 3 than other children (Table 2). Only $1.5 \%$ of families living in this district had a relatively high SES level and about $77 \%$ of them were classified as families with low income, educational and occupational levels. These findings highlight the need for planning to increase the level of awareness in the families in order to improve their lifestyle, nutrition and try to have more physical activities.

Several studies have reported time spent in watching $\mathrm{TV}$ or playing video games increased the risk of overweight/obesity in children [20, 24, 44]. Moreover, the results obtained in some studies revealed a negative correlation between inactivity/sedentary behavior and physical activities in children and adolescents [25, 45]. In our study, however, there was no statistically significant association between screen time and mild physical activities with anthropometric measures. The results of Table 2 revealed that, the subjects living in districts one and four were more likely to be at risk of obesity with respect to body fat measures and BMI indices than other groups. Adolescents living in these two districts had more physical activities and also spent more time in watching TV or playing computer games compared to other two groups (Table 1). Watching TV and other sedentary behaviors increases the consumption of the most advertised goods, including sweetened cereals, sweets, salty snacks, and sweetened beverages leading to increased appetite, energy intake, thus affecting the body weight in children [46]. Therefore, it seems that the presence of one behavior may be so strong that it cannot compensate for the presence of the other.

One of the strengths of the study was concerned with the results obtained in the random effects section in Table 3. The outcome variables were correlated at the districts and the subject levels, confirming the appropriateness of classifying the individual and district in the second and third hierarchical levels. The major portion of the total variance in TST (97.1\%), AST (97.7\%), and SST (97.5\%) was found at the child level, meaning that children with higher TST tend to have high AST and SST. Results also highlighted the importance of clustering in assessing the relationships between demographic characteristics and anthropometric measures.

The cross-sectional nature of the study could be considered as a limitation in this study, because, it is not clear how response variables are influenced by the covariates. Further studies could take a prospective and timebased approach to obtain more accurate results. Another limitation is the use of a single self-reported item to assess family history of obesity and it may have introduced a bias and underreporting of subjects. The lack of other predictor variables related to adolescent obesity such as eating habits, biological measures, as well as the selection of the district as the only variable in the third hierarchical level were also regarded as the third limitation of the study.

\section{Conclusion}

The results of multivariate multilevel analysis showed that sex, family history of obesity, and SES were significantly associated with three body fat measures and there were positive correlation between three outcomes at the child and district levels. Furthermore, these indices were more prevalent among the students living in districts 1 and 4 than other two districts. Therefore, it is suggested to develop effective interventions to prevent the effects of individual and environmental undesirable factors on childhood obesity in both family and community levels, especially in these two districts.

\section{Abbreviations}

BMI: Body mass index; ST: Skinfold thickness;i; WC: Waist circumference; TST: Triceps skinfold thickness; AST: Abdominal skinfold thickness; SST: Subscapular skinfold thickness; PA: Physical activity; SES: Socio-economic status; IGLS: Iterative generalized least squares

\section{Acknowledgements}

The present study was supported by a grant from the Vice-chancellor for Research, Shiraz University of Medical Sciences, Shiraz, Iran. The authors would also like to thank Center for Development of Clinical Research of Nemazee Hospital and Dr. Nasrin Shokrpour for editorial assistance.

\section{Authors' contributions}

MA contributed in analyzed the data, and interpreted the results, wrote the manuscript drafting. ST contributed in designed the study, analysis of data, interpretation the results. SMTA> contributed in interpretation the results and designed the study. RT and MA contributed in interpretation the results wrote the manuscript drafting. AA contributed in analysis of data and interpretation the results. All authors have read and approved the manuscript.

\section{Funding}

The research grant provided by Research Deputy of Shiraz University of Medical Sciences (No. 98-01-62-20366). Funding body of the study did not play any role in the design of the study, collection, analysis, and interpretation of data and in writing the manuscript. 


\section{Availability of data and materials}

The datasets used and/or analyzed during the current study available from the corresponding author on reasonable request.

\section{Ethics approval and consent to participate}

This study was approved by the ethics committee of Shiraz University of Medical Sciences. All Children gave oral consent and their parents gave written informed consent before participation in the study.

\section{Consent for publication}

Not applicable.

\section{Competing interests}

The authors declare that they have no competing interests.

\section{Author details}

${ }^{1}$ Health Policy Research Center, Institute of Health, Shiraz University of Medical Sciences, Shiraz, Iran. ${ }^{2}$ Department of Biostatistics, Medical School, Shiraz University of Medical Sciences, Shiraz, Iran. ${ }^{3}$ Department of Mathematics, Yasouj University, Yasouj, Iran.

\section{Received: 31 October 2019 Accepted: 28 April 2020} Published online: 02 May 2020

\section{References}

1. Wijnhoven TM, van Raaij JM, Spinelli A, Starc G, Hassapidou M, Spiroski I, et al. WHO European childhood obesity surveillance initiative: body mass index and level of overweight among 6-9-year-old children from school year 2007/2008 to school year 2009/2010. BMC Public Health. 2014;14(1):806.

2. Ogden CL, Fryar CD, Hales CM, Carroll MD, Aoki Y, Freedman DS. Differences in obesity prevalence by demographics and urbanization in US children and adolescents, 2013-2016. Jama. 2018;319(23):2410-8.

3. Rahmani A, Sayehmiri K, Asadollahi K, Sarokhani D, Islami F, Sarokhani M. Investigation of the prevalence of obesity in Iran: a systematic review and meta-analysis study. Acta Medica Iranica. 2015;53(10):596-607.

4. Rashidi H, Erfanifar A, Latifi SM, Payami SP, Aleali AM. Incidence of obesity, overweight and hypertension in children and adolescents in Ahvaz southwest of IRAN: five-years study. Diab Metab Syndr. 2019;13(1):201-5.

5. Djalalinia S, Kelishadi R, Qorbani M, Peykari N, Kasaeian A, Nasli-Esfahani E, et al. A systematic review on the prevalence of overweight and obesity, in iranian children and adolescents. Iranian J Pediatr. 2016;26:3.

6. Eshraghian A, Dabbaghmanesh MH, Eshraghian H, Fattahi MR, Omrani GR. Nonalcoholic fatty liver disease in a cluster of Iranian popula-tion: thyroid status and metabolic risk factors. Arch Iranian Med. 2013;16(10):584.

7. Freedman DS, Ogden CL, Kit BK. Interrelationships between BMl, skinfold thicknesses, percent body fat, and cardiovascular disease risk factors among US children and adolescents. BMC Pediatr. 2015;15(1):188.

8. Sahoo K, Sahoo B, Choudhury AK, Sofi NY, Kumar R, Bhadoria AS. Childhood obesity: causes and consequences. Journal of family medicine and primary care. 2015;4(2):187.

9. Fontaine $K R$, Redden DT, Wang C, Westfall AO, Allison DB. Years of life lost due to obesity. Jama. 2003;289(2):187-93.

10. Mahadevan S, Ali I. Is body mass index a good indicator of obesity? Springer; 2016.

11. Heydari S-T, Seyed-Mohammad-Taghi Ayatollahi NZ. Diagnostic value of bioelectrical impedance analysis versus body mass index for detection of obesity among students. Asian J Sports Med. 2011;2(2):68.

12. Addo OY, Himes JH. Reference curves for triceps and subscapular skinfold thicknesses in US children and adolescents. Am J Clin Nutr. 2010;91(3):635-42.

13. Ayatollahi SMT, Mostajabi F. Triceps skinfold thickness centile charts in primary school children in shiraz, Iran. Arch Iranian Med. 2008;11(2):210-3.

14. Yeung DCS, Hui SSC. Validity and reliability of skinfold measurement in assessing body fatness of Chinese children. Asia Pac J Clin Nutr. 2010;19(3): 350-7.

15. de Quadros TMB, Gordia AP, Andaki ACR, Mendes EL, Mota J, Silva LR. Utility of anthropometric indicators to screen for clustered cardiometabolic risk factors in children and adolescents. J Pediatr Endocrinol Metab. 2019;32(1): 49-55.

16. Kristiansen $\mathrm{H}$, Eide $\mathrm{GE}$, Brannsether $\mathrm{B}$, Roelants $\mathrm{M}$, Bjerknes $\mathrm{R}$, Júlíusson $\mathrm{PB}$. Associations between different weight-related anthropometric traits and lifestyle factors in Norwegian children and adolescents: a case for measuring skinfolds. Am J Hum Biol. 2018:30(6):e23187.

17. Nooyens AC, Koppes LL, Visscher TL, Twisk JW, Kemper HC, Schuit AJ, et al. Adolescent skinfold thickness is a better predictor of high body fatness in adults than is body mass index: the Amsterdam growth and health longitudinal study. Am J Clin Nutr. 2007;85(6):1533-9.

18. Dehghan M, Akhtar-Danesh N, Merchant AT. Childhood obesity, prevalence and prevention. Heart Views. 2006;7(2):74-82.

19. Khashayar P, Kasaeian A, Heshmat R, Motlagh ME, Gorabi AM, Noroozi M, et al. Childhood overweight and obesity and associated factors in iranian children and adolescents: a multilevel analysis; the CASPIAN-IV study. Front Pediatr. 2018;6.

20. Kelishadi R, Heidari Z, Kazemi I, Jafari-Koshki T, Mansourian M, Motlagh M-E, et al. A hierarchical Bayesian tri-variate analysis on factors associated with anthropometric measures in a large sample of children and adolescents: the CASPIAN-IV study. J Pediatr Endocrinol Metab. 2018;31(4):443-9.

21. Mistry SK, Puthussery S. Risk factors of overweight and obesity in childhood and adolescence in south Asian countries: a systematic review of the evidence. Public Health. 2015;129(3):200-9.

22. Zhou H, Yamauchi T, Natsuhara K, Yan Z, Lin H, Ichimaru N, et al. Overweight in urban schoolchildren assessed by body mass index and body fat mass in Dalian, China. J Physiol Anthropol. 2006;25(1):41-8.

23. Heelan KA, Bartee RT, Nihiser A, Sherry B. Healthier school environment leads to decreases in childhood obesity: the Kearney Nebraska story. Child Obes. 2015;11(5):600-7.

24. Gomes T, Katzmarzyk P, Santos F, de Chaves R, Santos D, Pereira S, et al. Are $\mathrm{BMl}$ and sedentariness correlated? A multilevel study in children. Nutrients. 2015;7(7):5889-904.

25. Gomes T, Hedeker D, dos Santos F, Souza M, Santos D, Pereira S, et al. Relationship between sedentariness and moderate-to-vigorous physical activity in youth: a multivariate multilevel study. Int J Environ Res Public Health. 2017;14(2):148.

26. Heshmat R, Qorbani M, Ghoreshi B, Djalalinia S, Tabatabaie OR, Safiri S, et al. Association of socioeconomic status with psychiatric problems and violent behaviours in a nationally representative sample of Iranian children and adolescents: the CASPIAN-IV study. BMJ Open. 2016;6(8):e011615.

27. Group WMGRS. WHO Child Growth Standards based on length/height, weight and age. Acta Paediatrica (Oslo, Norway: 1992) Supplement. 2006; 450:76.

28. Md O, Onyango AW, Borghi E, Siyam A, Nishida C, Siekmann J. Development of a WHO growth reference for school-aged children and adolescents. Bull World Health Org. 2007;85:660-7.

29. Ayatollahi SMT, Bagheri Z, Heydari ST. Agreement analysis among measures of thinness and obesity assessment in Iranian school children and adolescents. Asian J Sports Med. 2013;4(4):272-80.

30. Goldstein H. Multilevel statistical models: John Wiley \& Sons; 2011.

31. Hox JJ, Moerbeek M, van de Schoot R. Multilevel analysis: techniques and applications (quantitative methodology). New York: Taylor \& Francis; 2010.

32. De Onis M, Borghi E, Arimond M, Webb P, Croft T, Saha K, et al. Prevalence thresholds for wasting, overweight and stunting in children under 5 years. Public Health Nutr. 2019;22(1):175-9.

33. Pulgaron ER. Childhood obesity: a review of increased risk for physical and psychological comorbidities. Clin Ther. 2013;35(1):A18-32.

34. Sanders RH, Han A, Baker JS, Cobley S. Childhood obesity and its physical and psychological co-morbidities: a systematic review of Australian children and adolescents. Eur J Pediatr. 2015;174(6):715-46.

35. Rankin J, Matthews L, Cobley S, Han A, Sanders R, Wiltshire HD, et al. Psychological consequences of childhood obesity: psychiatric comorbidity and prevention. Adolescent Health Med Ther. 2016;7:125.

36. Kelishadi R, Haghdoost A-A, Sadeghirad B, Khajehkazemi R. Trend in the prevalence of obesity and overweight among Iranian children and adolescents: a systematic review and meta-analysis. Nutrition. 2014;30(4):393-400.

37. Baygi F, Dorosty AR, Kelishadi R, Qorbani M, Asayesh H, Mansourian M, et al. Determinants of childhood obesity in representative sample of children in North East of Iran. Cholesterol. 2012. https://doi.org/10.1155/2012/875163.

38. Selvi A, Naaraayan SA, Priyadharishini D, Begum NS. Comparison of various body fat indices in early and mid-adolescents of South India: school-based cross-sectional study. Indian J Child Health. 2018:124-7.

39. Chung AE, Skinner AC, Steiner MJ, Perrin EM. Physical activity and BMI in a nationally representative sample of children and adolescents. Clin Pediatr. 2012;51(2):122-9. 
40. Li L, Yin J, Cheng H, Wang Y, Gao S, Li M, et al. Identification of genetic and environmental factors predicting metabolically healthy obesity in children: data from the BCAMS study. J Clin Endocrinology Metab. 2016;101(4):1816-25.

41. Portela DS, Vieira TO, Matos SM, de Oliveira NF, Vieira GO. Maternal obesity, environmental factors, cesarean delivery and breastfeeding as determinants of overweight and obesity in children: results from a cohort. BMC Pregnancy Childbirth. 2015;15(1):94.

42. Bahreynian M, Motlagh ME, Qorbani M, Heshmat R, Ardalan G, Kelishadi R. Prevalence of growth disorders in a nationally representative sample of Iranian adolescents according to socioeconomic status: the CASPIAN-III study. Pediatri Neonatology. 2015;56(4):242-7.

43. Yusefzadeh H, Rahimi B, Rashidi A. Economic burden of obesity: a systematic review. Soc Health Behav. 2019;2:7-12.

44. Schmidt ME, Haines J, O'brien A, McDonald J, Price S, Sherry B, et al. Systematic review of effective strategies for reducing screen time among young children. Obesity. 2012;20(7):1338-54.

45. Leech RM, McNaughton SA, Timperio A. The clustering of diet, physical activity and sedentary behavior in children and adolescents: a review. Int $J$ Behav Nutr Phys Act. 2014;11(1):4.

46. Carandente F, Roveda E, Montaruli A, Pizzini G. Nutrition, activity behavior and body constitution in primary school children. Biol Sport. 2009;26:4

\section{Publisher's Note}

Springer Nature remains neutral with regard to jurisdictional claims in published maps and institutional affiliations.

Ready to submit your research? Choose BMC and benefit from:

- fast, convenient online submission

- thorough peer review by experienced researchers in your field

- rapid publication on acceptance

- support for research data, including large and complex data types

- gold Open Access which fosters wider collaboration and increased citations

- maximum visibility for your research: over $100 \mathrm{M}$ website views per year

At $\mathrm{BMC}$, research is always in progress.

Learn more biomedcentral.com/submissions 